\title{
Regional seismicity and seismic wave propagation from records at the Tonto Forest Seismological Observatory, Payson, Arizona
}

\author{
S. J. DUDA
}

Ricevuto il 10 Agosto 1965

Stmmary. - The records of the Tonto Forest Seismological Observatory near Payson, Arizona, have been used to investigate the applicability of an array station for the study of local seismicity and seismic wave pro. pagation at short epicentral distances. Inferences are drawn about the seismicity of Arizona and the characteristics are given for two earthquake sequences, in Imperial County, California, and in Baja California.

The records of the earthquakes and a selection of quarry blasts are used for the study of the propagation of crustal waves. According to their group velocities and appearance, the $S g$ and $P^{*}$-waves observed at small epicentral distances are identical with the $L g 2$ and $\pi g$-wave respectively, observed at larger epicentral distances.

The ratio of $S$ to $P$ wave energy is estimated to be of the order of $100: 1$ for earthquakes at an epicentral distance of about $14 \mathrm{~km}$. The attenuation of $S g$-wave energy has a discontinuity at an epicentral distance of $325 \mathrm{~km}$ and possibly another at $100 \mathrm{~km}$. Because of this fact an appreciable difierence of seismic energies recorded at two epicentral distances, slightly below and above these critical distances, will be observed. The duration of the $S g$-phase depends mainly on the magnitude of the earthquakes.

A magnitude-energy conversion formula is derived in the form:

$$
\log E=10.06+(2.17 \pm 0.07) H_{L}
$$

for the magnitude range $-0.7<M_{L}<+4.9$ and the distance range 14 $\mathrm{km} \leq \Delta<640 \mathrm{~km}$.

Rtassunto. - Allo scopo di indagare sull'opportunitì di una stazione sismica a disposizione ordinata, per lo studio della sismicità locale e della propagazione delle onde sismiche per brevi distanze epicentrali, sono state usate le registrazioni ottenute nell'Osservatorio Sismologico di Tonto Forest, 
presso Payson (Arizona). Sono state tratte conclusioni circa la sismicità dell'Arizona e sono state date le caratteristiche per due serie di terremoti, avvenuti rispettivamente a Imperial County, California, e a Baja California.

Per lo studio della propagazione delle onde attraverso la crosta, sono state usate sia registrazioni di terremoti sia registrazioni selezionate di esplosioni fatte in cava. In hase alle velociti di gruppo ed al loro inizio, le onde $S g$ e $P^{*}$ osservate per piccole distanze epicentrali, si identificano rispettivamente alle onde $L g 2$ e $\pi g$ osservate per distanze epicentrali molto più grandi.

Il rapporto fra l'energia delle onde $S$ e quella delle onde $P$ è stato dell'ordine di $100: 1$, per terremoti con distanze epicentrali intorno ai $14 \mathrm{~km}$. Lattenuazione dell'energia delle onde $S g$ la una discontinuitì per una distanza epicentrale di $325 \mathrm{~km}$ ed un'altra probabile a $100 \mathrm{~km}$. Per questa ragione verrì notata una notevole, differenza fra le energie sismiche registrate a due distanze epicentrali, leggermente superiori o inferiori alle suddette distanze critiche. La durata della fase $S g$ è legata principalmente alla magnitudo dei terremoti.

E stata ottenuta la formula che lega la magnitudo all'energia espressa nella forma:

$$
\log E=10.06+(2.17 \pm 0.07) M_{L}
$$

valida per $-0.7 \leqslant M_{L} \leqslant+4.9$ e per $14 \mathrm{~km} \leqslant d \leqslant 640 \mathrm{~km}$.

\section{1. - Introduction.}

In the last years a new technique of recording seismic waves was introduced by seismic array stations. I) to the large magnification of the individual array seismographs, of the order of millions, as well as the possibility to increase the ratio between signal and noise, array stations offer the advantage of highest perceptibility of events. However, before the advantages and shortcomings of an array station in comparison with a conventional seismograph station can be weighed we must attempt to solve different seismological problems by means of it.

The first purpose of the present investigation is to draw methodical conclusions on the applicability of an array station for the study of regional seismicity and seismic wave propagation. The accuracy in epicentral distance and azimuth determination is estimated. The increase of the minimum recorded magnitude with epicentral distance is determined. The possibilities of finding the attenuation of seismic waves are presented. From this, inferences about the optimal relative position of two or more array stations are drawn. 
The second purpose of the investigation is to give several direct seismological results concerning:

1. some aspects of the seismicity of Arizona and of two earthquake sequences, in Imperial County, California (Imperial Talley), and Baja California,

2. the wave propagation at shortest epicentral distances.

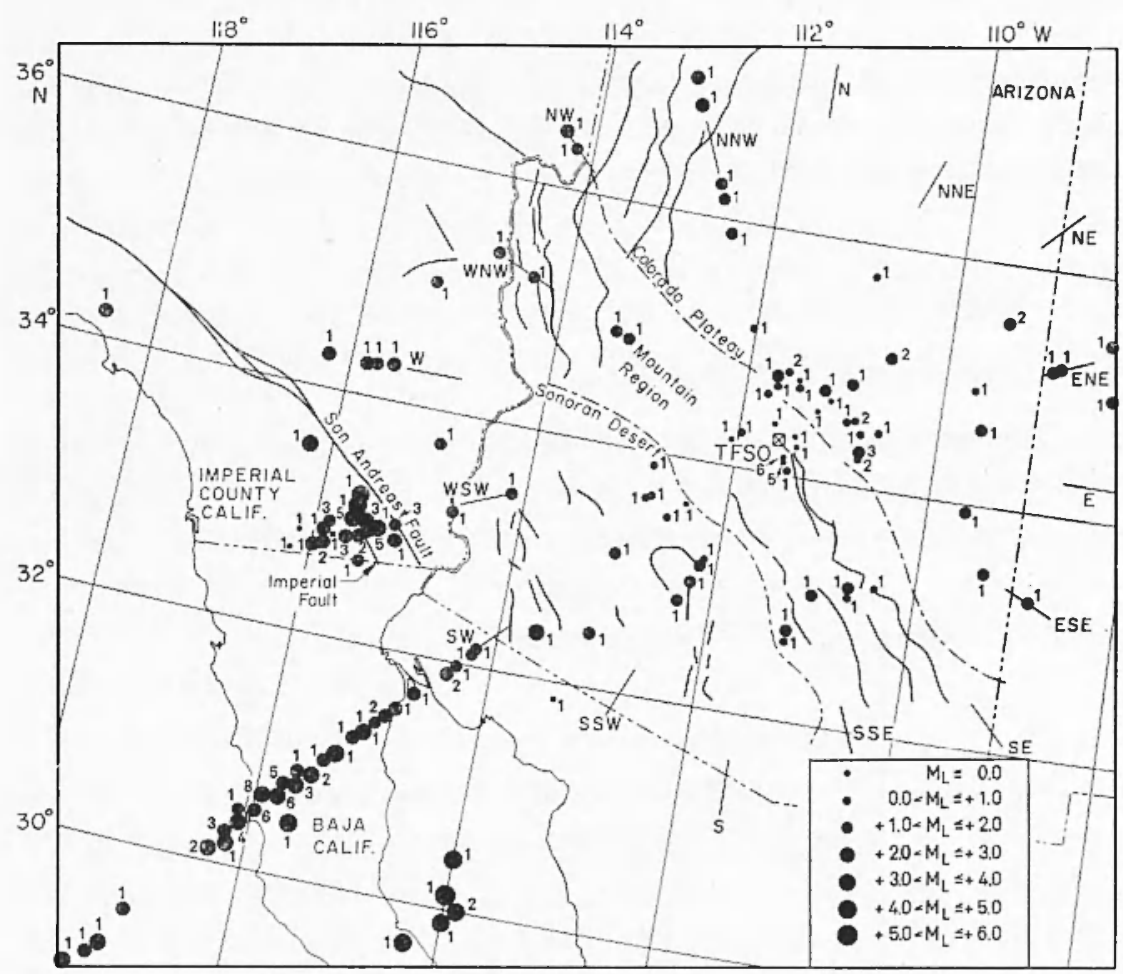

Fig. 1 - Epicentral map of Arizona for earthquakes in the time interval Sep. 15, 1963-Jan. 31, 1964, Imperial County, California, for earthquakes on Oct. 27, 1963, and Baja California, for earthquakes on Nov. 23-31, 1963.

The present paper is based on records from the Tonto Forest Seismological Observatory (TFSO) near Payson, Arizona.

TFSO $\left(34^{\circ} 16^{\prime} 04^{\prime \prime} \mathrm{N}, 111^{\circ} 16^{\prime} 13^{\prime \prime} \mathrm{W}\right)$ is situated close to the centre of Arizona (Fig. 1). The epicentral distance of Arizona events recorded at TFSO lies within $3^{\circ}$.

The propagation of seismic waves in this distance range was investigated from records of earthquakes as well as explosions, the latter originating in the numerous quarries in some parts of Arizona. 
Differences in records from earthquakes and explosions allowed a fair separation of the two kinds of events in this distance range. An epicentral map of Arizona earthquakes is presented.

In the present study two eartliquake sequences were included: from Imperial County. California, and from Baja California. The epicentral distances in the first sequence range from $2.8^{\circ}$ to $4.1^{\circ}$, and in the second sequence from $3.0^{\circ}$ to $5.8^{\circ}$. In the case of earthquake sequences from a limited area the chance of including an explosion is negligible. The characteristics of these two earthquake sequences were found, and the study of seismic wave propagation was extended to the epicentral distance range from $2.8^{\circ}$ to $5.8^{\circ}$.

2. - Observational data.

\section{1. - Instruments and magnitudes.}

The seismographs at the TFSO form two arrays: an areal array with a diameter of $3.8 \mathrm{~km}$, and a linear or "S-wave type" array, with

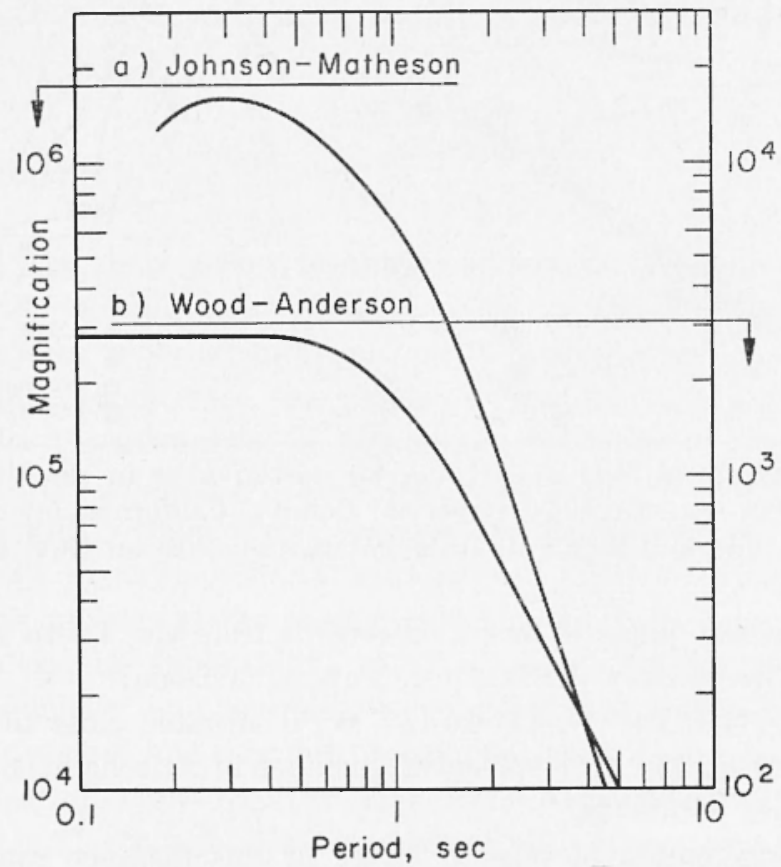

Fig. 2 - Response characteristics for a) Johnson-Matheson array seismometer, and $b$ ) standard Wood-Anderson torsion seismometer. 
a length of $10.4 \mathrm{~km}$ of each one of two perpendicular seismograph lines in the shape of a cross.

For our study the records of a 3-component set of seismometers situated in the centre of the array, and 4 vertical seismometers situated at the ends of the linear array were used. All seismometers operated with a maximum magnification of $1,600,000$ at a period of $0.3 \mathrm{sec}$ throughout the time interval investigated. On the records measured $1 \mathrm{sec}$ corresponds to about $1 \mathrm{~cm}$.

Fig. 2 shows the frequency response characteristic of a single array seismometer (Johnson-Matheson) and that of the standard WoodAnderson torsion seismometer. Besides their maximum magnification, the differences in the characteristics are considered small. Therefore the magnitudes $M_{L}$ of the shocks could be determined according to the original definition by Richter (1935), without the necessity of a transformation of our records into such as would be obtained by the torsion seismometer.

Table I lists all of our earthquakes whose magnitudes $M_{L}$ were determined from the TFSO as well as from Pasadena records. The mean magnitude difference is small, and amounts to 0.2. This difference may be a result of:

(a) the above-mentioned difference in the response characteristics of the instruments used,

(b) the radiation pattern of the earthquakes, and

(c) the station correction needed for TFSO.

In view of the small difference in response characteristics, and the fact that the radiation pattern for small shocks is obliterated by horizontal refractions (Bune \& al. 1960), the magnitude difference of 0.2 may be considered as tentative "station correction" for the horizontal seismographs, whose records were used for the magnitude determination in our study. However, the introduction of it into our calculations seems premature, since it could be based on only 8 cases.

\section{2. - Seismograms and accuracy.}

For this study the records and the TFSO-bulletin for the time from September 15, 1963, to January 31, 1964, were at our disposal. The following events were examined:

(a) all earthquakes within the epicentral distance of $3^{\circ}$ in this time interval, amounting to 82 ; 
Table I - ResUlts From EARTIQUAKES FOR WHICH USCGS INFORMation WAS aVAILABLe.

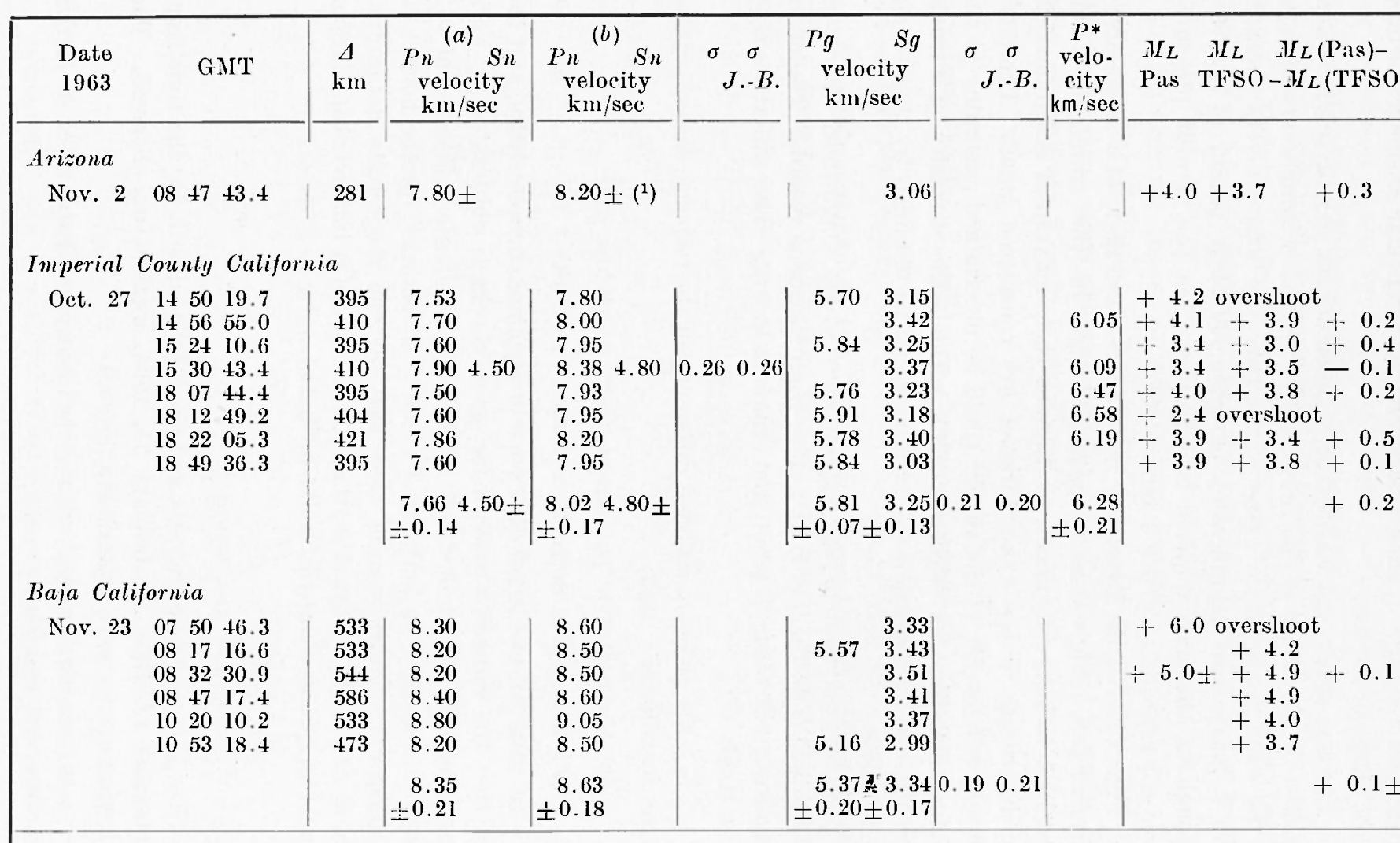

(1) Computed on the assumption of a $P q$-velocity equal to that from Imperial County. (a), (b) see Section 4.1 . 
(b) a selection of 93 explosions in the distance range from $1^{\circ}$ to $3^{\circ}$;

(c) the earthquakes on October 27, 1963, in Imperial County, California, amounting to 50 ; and

(d) the earthquakes in the time from November 23 to 31,1963 , in Baja California, amounting to 64 .

A shock was accepted if at least one $S$ - and one $P$-wave could be identified. The $S q$-phase was the most prominent in the entire epicentral distance range investigated. Magnitudes were based exclusively on $S g$. Up to about $1^{\circ}$ the $P g$-phase, and beyond that distance, the additional $P n$-phase, could usually be found. Sometimes, especially for stronger shocks, the $P^{*}$ - and $S n$-phases were present.

Arrival times, amplitudes and periods of the compressional phases $\left(P n, P^{*}, P g\right)$ were determined from the vertical component and of the distortional phases $\left(S n, S^{*}, S g\right.$ ) from the horizontal components of the central 3-component set of seismographs.

All independent time-differences between the phases were used in the determination of the epicentral distances.

The travel times for crustal phases at zero focal depth, as given by Jeffreys \& Bullen (1958), were used. The travel times can be expected to differ from those in the investigated regions. The disagreement of epicentral distances calculated from two or more phase differences increased with epicentral distances. At $3^{\circ}$ it was generally lower than $0.2^{\circ}$ and reached only exceptionally $0.5^{\circ}$ at the largest epicentral distances considered. If the local travel times were known, the accuracy of epicentral distance determination could be increased, as well as the focal depth determined. The azimuth towards the epicentre was found from the differences in arrival time of the first $P$-phase on the 5 vertical seismometers, situated at the very ends of the linear arrays and in the centre. The azimuths at epicentral distances up to $3^{\circ}$ are accurate to $\pm 11.25^{\circ}$ or even less. For epicentral distances beyond $3^{\circ}$, however, the determination of the azimuths is more critical. The reason is that the first events become difficult to identify, and no accurate time reading or phase correlation on different traces is possible (Richter 1958). The epicentres for Imperial County and Baja California in Fig. 1 therefore appear on a line, the azimuth being accurate to about $\pm 22.50^{\circ}$, unless the epicentre was reported by USCGS. 


\section{3. - Perceptibility of earthquaties by the station.}

Fig. 3 shows the magnitudes $M_{L}$ of the earthquakes investigated as a function of the epicentral distance. The increase of minimum Inagnitude with distance is nonlinear in the epicentral distance range from 0 to about $600 \mathrm{~km}$. In particular, there is a rapid increase of minimum magnitude at the shortest epicentral distances. This means that earthquakes with low magnitudes can be recorded only if the epicentre is situated close to the station.

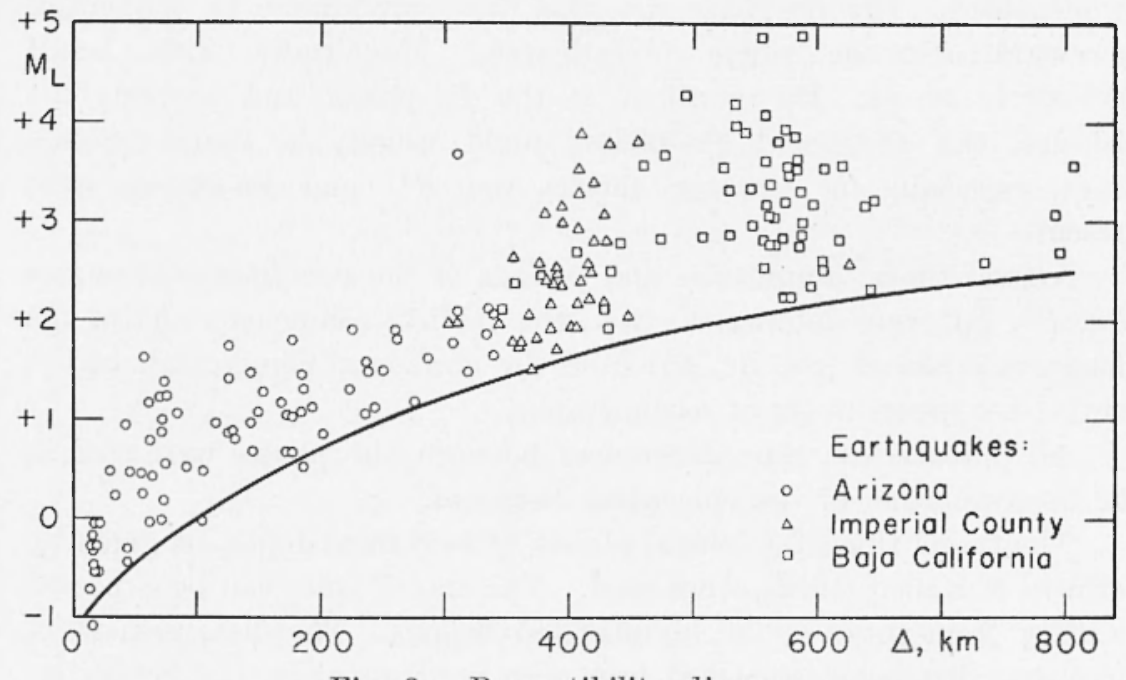

Fig. 3 - Perceptibility diagram.

The poor perceptibility to earthquakes with low magnitudes can be understood in terms of higher absorption of shortperiod than longperiod waves. Although the magnitude does not take into account the wave period directly, it is well known that the wave spectrum generated by earthquakes with low magnitudes has a maximum at shorter period than those for earthquakes with larger magnitudes. The shortperiod content of the spectrum of earthquakes with any magnitude is absorbed at small hypocentral distances, and at larger distances only the longperiod part can be recorded. Since the latter has a low intensity for earthquakes with small magnitudes, their range of perceptibility is small.

From the diagram in Fig. 3 we see immediately that the number of earthquakes can be complete only for $M_{L} \geqslant+1.5$ in Arizona, for $M_{L} \geqslant+2.0$ in Imperial County and for $M_{L} \geqslant+2.7$ in Baja California. 
On the other hand, the maximum magnitude which can be determined at a certain epicentral distance is limited by the magnification of the seismographs. Therefore, magnitudes could not be determined for 4 earthquakes in Imperial County and 1 earthquake in Baja California, though reported by Pasadena. There were 5 earthquakes in Arizona. not recorded in Pasadena, but recorded at the TFSO with amplitudes too large to allow a magnitude determination. Most of the shocks investigated in each of the regions were recorded exclusively by the TFSO.

\section{3. - Seismicity.}

\section{1. - Epicentral map of Arizona.}

In the past the seismicity of Arizona has been investigated only sporadically. Townley and Allen (1939) published a descriptive catalogue of Arizona earthquakes in the interval 1769 to 1928. Woollard (1951) presented a map with earthquake epicentres of the Rocky Mountain region from USCGS reports. This map includes 21 epicentres in Arizona for an interval of "several years" up to 1949 .

In this study, high sensitivity of the seismographs causes that besides earthquakes a considerable number of artificial events, especially quarry blasts, is recorded. This raises the problem of distinguishing between earthquakes and explosions.

For Arizona events the following criteria were applied jointly to separate earthquakes from explosions:

(a) the position of the epicentre, if compared with the position of working mines in Arizona;

(b) the origin time of the event, if related to working time and habits;

(c) the ratio of $S$ - to $P$-wave energy recorded (see Section 5.1).

If an earthquake happened underneath a site with mines, however, it could be misinterpreted as explosion. This is true especially for the region bounded by the longitudes $110^{\circ}$ and $111^{\circ} \mathrm{W}$ and latitudes $31.5^{\circ}$ and $33.5^{\circ} \mathrm{N}$, situated towards the SSE of TFSO, where many explosions took place in the investigated time interval (Fig. 1). No explosion is believed to be misinterpreted as earthquake.

Fig. 1 shows the epicentres of all earthquakes in Arizona in the investigated time interval. The magnitudes of 77 earthquakes lie in the range from -0.7 to +2.1 , with a single shock of magnitude +3.7 
(Table I). There was possibly even a shock witl a magnitude as low as -1.1 . However, only the $S g$-phase could be identified. The epicentre of this earthquake was assumed to be identical with another one, which oceurred 23 minutes earlier.

On the epicentral map a considerable scatter of epicentres is seen, which can be only partially related to the errors in epicentre determination. It appears that earthquakes with low magnitudes are distributed over most of Arizona. The seismicity was low in terms of number of shocks and their magnitudes. From the stronger shocks it is seen that besides the slightly indicated NW-SE striking belt of seismicity, as already reported by Woollard (1951), there is a branch running from the middle of Arizona towards the SW so as to meet the region of strong seismicity in Baja California.

\section{2. - Some tectonic features of the investigated regions.}

The genesis of the present seismicity of any region may be looked for in the most recent tectonic history of the recrion considered. Past tectonic events have importance for the present seismicity; the younger they are and the more intensive they were the greater is the seismicity.

We were looking for such characteristic features in the tectonic history of Arizona, Imperial County and Baja California, which are capable to influence the present seismicity of these regions. Some differences of the characteristic features, implying differences in the occurrence of earthquakes in the three regions are pointed out.

Arizona and Imperial County turn out to be strong relative contrasts from the point of view of the genesis of seismic activity.

Arizona, belonging partially to the Basin and Range Province, underwent the latest orogeny in the late Mesozoic and early Tertiary with considerable folding, thrusting and volcanic activity, the latter continuing up to very recent time. As a contrast, the adjacent coastal California, including the Imperial County, has had little volcanism since the Miocene. It is believed that the present is a time of typical orogeny in southern California. Whereas any present seismicity of Arizona may be expected to be related to orogenetic events with volcanic activity, the seismic activity in Imperial County is related to movements on the San Andreas Fault system, and is probably connected with the Imperial Fault.

Baja California occupies an intermediate position. Volcanism has continued since Miocene and Pleistocene up to the present time, but 
Tertiary and Quaternary uplift of the peninsula, as well as faulting continuing during Quaternary along some fault zones, are known. Earthquake activity in Baja California may therefore be related to both tectonic movements and volcanic processes in the peninsula. For details of the tectonical development of the regions, see Eardley (1951).

\section{3. - Recurrence diagrams.}

The number of earthquakes in a certain magnitude range was found to increase exponentially with decreasing magnitudes (Gutenberg \& Richter 1954):

$$
\log n=a-b M
$$

where $n$ is frequency, i.e. number of earthquakes in the magnitude range $M \pm \delta M$,

$M$ the magnitude of the earthquake, and

$a, b$ constants.

All logarithms in this paper are to the base 10 . The constants $a, b$ are used to characterize the seismicity of a region. The constant $b$ is independent of the time interval and epicentral area chosen (or volume drawn by the hypocentres), and gives the relative proportion of shocks with different magnitudes. Both $a$ and $b$ may vary in a region in course of time, as also from region to region.

The law expressed by [3.1] has been confirmed repeatedly for shocks with large magnitudes $(M \geqslant 6)$. The question arises whether there is a lower magnitude limit for its validity. Asada (1957) found it to be valid in the magnitude range from -1 to +5 in Japan. Sanford \& Holmes (1962) found it to satisfy earthquakes with seismic energies as low as $10^{7} \operatorname{ergs}\left(M_{L} \simeq-1.4\right)$.

From the 77 earthquakes with known magnitudes in Arizona, 46 in Imperial County and 63 in Baja California, the recurrence diagrams could be constructed.

Formula [3.1] cannot be applied if there is no earthquake for a certain magnitude inside the range considered. Since this is found in our case (Fig. 4), the cumulative frequencies $N$ were calculated, giving the number of earthquakes above the magnitude $H_{L}$ :

$$
\log N=a^{\prime}-b M_{L}
$$

the $b$-coefficients in [3.1] and [3.2] being identical (Utsu 1961).

Fig. 4 shows the frequency and cumulative frequency for our three populations of earthquakes. $M_{L}$ is counted in steps of 0.1 unit each. 


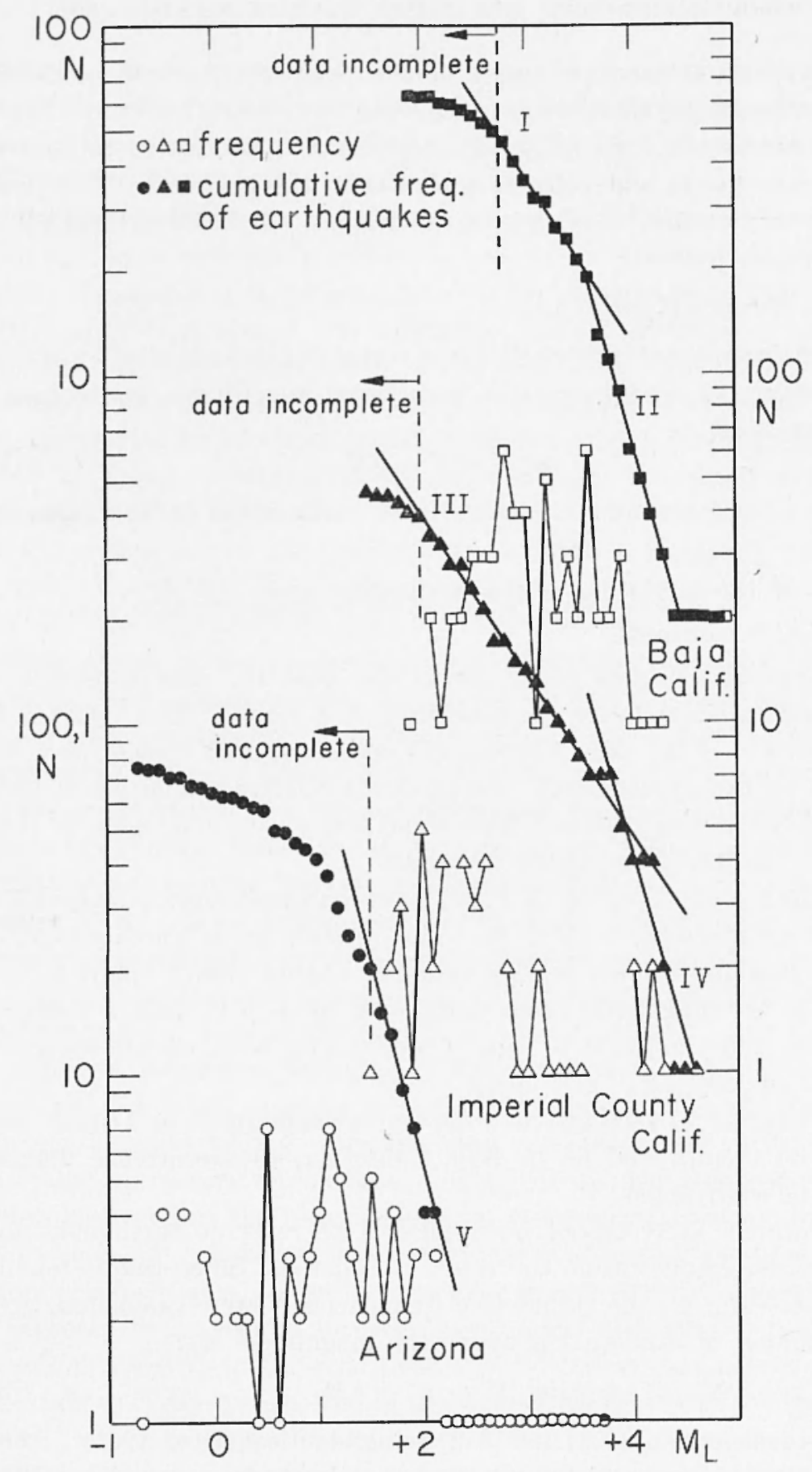

Fig. 4 - Recurrence diagram. The right-hand scale refers to Imperial County. 
From the cumulative frequeney diagrams we see immediately that the data are incomplete below the magnitude limits already found (Section 2.3). Above these limits the cumulative frequency diagrams can be approximated by equations of the form [3.2].

For Baja California we observe two branches, approximated by the following equations:

$$
\left.\begin{array}{l}
\text { branch I }: \log N=4.96-0.47 M_{L}:+2.7 \leqslant M_{L} \leqslant+3.6 \\
\text { branch II: } \log N=7.25-1.11 M_{L} ;+3.7 \leqslant M_{L} \leqslant+4.5
\end{array}\right\}
$$

The change of slope at $M_{L}=3.65$ is such that below this magnitude $\left(+2.7 \leqslant M_{L} \leqslant+3.6\right.$ ) the number of shocks increases slower with decreasing magnitude than in the higher magnitude range $(+3.7 \leqslant$ $\left.M_{L} \leqslant+4.5\right)$. In the diagram for Baja California an earthquake with magnitude $M_{L}=6$ (Nov. 23, 1963, $075046.3 \mathrm{GMT}, 30.1 \mathrm{~N}, 114.0 \mathrm{~W}$ ) which started the sequence, is not included. No earthquakes occurred in the magnitude range from 6.0 to 4.9 . This sequence has therefore the appearance characteristic for aftershock sequences, with a magnitude difference between the main shock and the largest aftershock equal to 1.1. This is in very good agreement with the so-called Båth's law (Richter 1958). The sequence was investigated for 9 days, after which the seismic activity in the area dropped to about the level of the preceding time.

The Imperial County sequence has the appearance of an earthquake swarm with no outstanding earthquake. The cumulative frequency diagram (Fig. 4) can be approximated by the equations:

$$
\begin{aligned}
& \text { branch III: } \left.\log N=3.51-0.46 M_{L}:+2.0 \leqslant M_{L} \leqslant+4.2\right) \\
& \text { branch IV } \left.: \log N=5.92-1.07 M_{L} ;+3.8 \leqslant M_{L} \leqslant+4.6\right)^{[3.4]}
\end{aligned}
$$

Here again two branches are needed for the approsimation. The magnitude limits overlap in the middle of the range, with practically no importance for the approximation. The $b$-coefficients for Baja California and Imperial County exhibit a remarkable agreement in the corresponding magnitude ranges.

For Arizona one branch was found. The approximation, yielding:

branch V: $\log N=3.11-1.21 M_{L} ;+1.5 \leqslant M_{L} \leqslant+2.1[3.5]$ is vague, since only 20 earthquakes can be taken into account.

The most surprising conclusion from the above approximations is that the $a$ - and $b$-coefficients in [3.1] can be different in the same region and time interval, but for differing magnitude ranges. The 
$b$-coefficient decreases with decreasing magnitude. The values of $b$ found here are well comparable with those found repeatedly for greater magnitudes.

4. - WaVe propagation.

4.1. - Phases.

For the present purpose the $P n$ and $S n$-waves are understood as refracted dilatational and distortional waves respectively travelling in the upper mantle. The $P g$ and $S g$-waves are assumed to be guided waves travelling in the earth's crust, their apparent surface velocity being equal to the group velocity in the crustal wave guide. Similarly, the $P^{*}$-wave is assumed to be a guided wave.

Table I lists the group velocities with standard deviation for those investigated earthquakes, whose origin times and epicentres have been reported by USCGS.

We note immediately that the $P g$ and $S g$-velocities are lower than usually found.

The $P n$ and $S n$-velocities were calculated for a crustal layer with constant velocities and a thickness of $28 \mathrm{~km}$, in agreement with models given by different authors (Tatel \& Tuve 1955, Press 1960, Berg \& al. 1960, Diment \& al. 1961, Pakiser \& Hill 1963). Two cases of crustal velocities were considered and the corresponding $P n$ and $S n$-velocities are presented in Table I:

(a) the mean velocity of the $P$-wave was taken as $6.3 t \mathrm{~km} / \mathrm{sec}$ in accordance with a finding for southern California (Richter 1958, p. 698) and the mean velocity of the $S$-wave was taken as $6.34 \mathrm{~km} / \mathrm{sec}$ : $\sqrt{3}=3.66 \mathrm{~km} / \mathrm{sec}$;

(b) the mean velocities were taken as equal to the $P g$ and $S g-$ velocities found for the respective profiles (Pakiser \& Hill 1963).

The $P n$-velocities are in both cases higher along the more southerly profile from Baja California than from Imperial County (Table I and Fig. 1).

The velocities found for the $P n$-wave from Imperial County under assumption (a) agree within error limits with the $P$-velocity (below $8 \mathrm{~km} / \mathrm{sec}$ ) in the Basin and Range Province (Pakiser 1963).

This would indicate that the mantle with anomalously low Pnvelocities terminates in Baja California. 
Special care has been taken to identify the pertinent phases in all examined records. The identification is proved to have been successful in the case of the $P n, S n$, and $P g, S q$-phases by Poisson ratios $(\sigma)$ calculated for the upper mantle and the crust respectively (Table I). The ratio $(\sigma)$ is in all cases in close agreement with the ratio determined from Jeffreys \& Bullen tables $\left(\sigma_{J B}\right)$. The Poisson ratio is seen to be higher in the upper mantle than in the crust.

The velocities and appearance of the crustal phases, observed in the distance range from $14 \mathrm{~km}$ up to more than $650 \mathrm{~km}$, were used to find out if they can be related to crustal phases observed at larger epicentral distances.

The velocities of the $S g$-phase, generally the strongest in our records, were $3.34 \pm 0.17 \mathrm{~km} / \mathrm{sec}$ for earthquakes in Baja California, $3.25 \pm$ $0.13 \mathrm{~km} / \mathrm{sec}$ for Imperial County and $3.06 \pm \mathrm{km} / \mathrm{sec}$ for Arizona, i. e. close to the velocity of the $L g 2$-phase $(3.37 \pm 0.04 \mathrm{~km} / \mathrm{sec})$ at larger epicentral distances (Bâth 1954). This is in agreement with the idea that the $L g$-phase is identical with the $S q$-phase, as expressed by Press and Ewing (1952).

The $P^{*}$-phase was recorded from a number of earthquakes in Imperial County (Table I). The mean velocity amounts to $6.28 \pm 0.21$ $\mathrm{km} / \mathrm{sec}$. The wave had small amplitudes in comparison to other phases and erratic occurrence. Both its velocity and appearance are close to that found by Press \& Gutenberg (1956) for the $\pi g$-wave at distances from $5.3^{\circ}$ to $37.5^{\circ}$ with a velocity of $6.09 \pm 0.06 \mathrm{~km} / \mathrm{sec}$.

The $\pi g$-phase has been proposed as corresponding to the $P g$-phase. The $P q$-phase was second in intensity in the entire distance range investigated. This is strange if indeed it should be identical with the

Table II - Corresponding pilase symbols at different distances.

\begin{tabular}{|l|l|lr|}
\hline \multicolumn{3}{|c|}{ Epicentral distances of about } \\
\hline$\leqslant 6^{\circ}$ & $\geqslant 6^{\circ}$ & $\leqslant 6^{\circ}$ & $\geqslant 6^{\circ}$ \\
\hline$P n$ & $P n$ corresponds to & $S n$ & $S n$ \\
$P^{*} \begin{array}{l}\text { probably } \\
\text { identical with }\end{array}$ & $x g$ corresponds to & & $L g 1$ \\
$P g$ & $P g$ corresponds to & $S g$ identical with $L g 2$ \\
\hline
\end{tabular}


rq-pliase. The same conclusion has been drawn previously by Båth (1962). From our observation we conclude rather that the $\pi g$-phase at large epicentral distance is identical with the $P^{*}$-phase at small epicentral distances.

In Table II are listed the phases which correspond to each other.

\section{2. - Periods of $P n, P g$ and Sg-vaves.}

If scismic events are recorded by a single station, even an array station, the seismograms usually differ from each other in the magnitude of the event and its epicentral distance. This makes it difficult to separate the effects of magnitude and distance. Nevertheless, in a number of cases it could be found which of these two factors is of prevailing importance.

The periods of the maximum oscillation of $P n$ and $P g$-waves on the vertical seismograph and of $S g$-waves on the horizontal seismographs were measured, together with the corresponding amplitudes. As only slight changes of period with time were observed, the periods correspond in general to most of the wave train of each phase.

The periods of the $P n, P g$, and $S q$-waves as function of magnitude display a large scatter. We conclude that the influence of the magnitude of the earthquake on the period of the maximum oscillation of each phase is below the measuring accuracy or is masked by another factor.

The periods as function of epicentral distance reveal a general increase with distance, as seen in Fig. 5. The dashed lines are overall least-square approximations, their equations being shown in Table III.

The $P n$-period is practically constant within the distance ranges from $100 \mathrm{~km}$ to $300 \mathrm{~km}$, and from $300 \mathrm{~km}$ to $650 \mathrm{~km}$ as indicated by the small correlation coefficients shown in Table III for the $P n$-period in both distance ranges.

The $P g$-period increases with distance up to $100 \mathrm{~km}$, remains fairly constant between $100 \mathrm{~km}$ and $300 \mathrm{~km}$ epicentral distance (small correlation coefficient), and increases thereafter.

The $S g$-period is constant in the range from $14 \mathrm{~km}$ to $100 \mathrm{~km}$, where it jumps $0.15 \mathrm{sec}$, and remains constant up to $300 \mathrm{~km}$. Here it starts to scatter strongly and increases rapidly with distance, meeting the periods found for $L g$-waves (Båth 1962). If the critical distance for the $S q$-wave is chosen at $350 \mathrm{~km}$ instead of $300 \mathrm{~km}$, even a jump of the period by a factor of 2 is indicated by the data. However, we kept in all cases the critical distance for the least-square approximation 


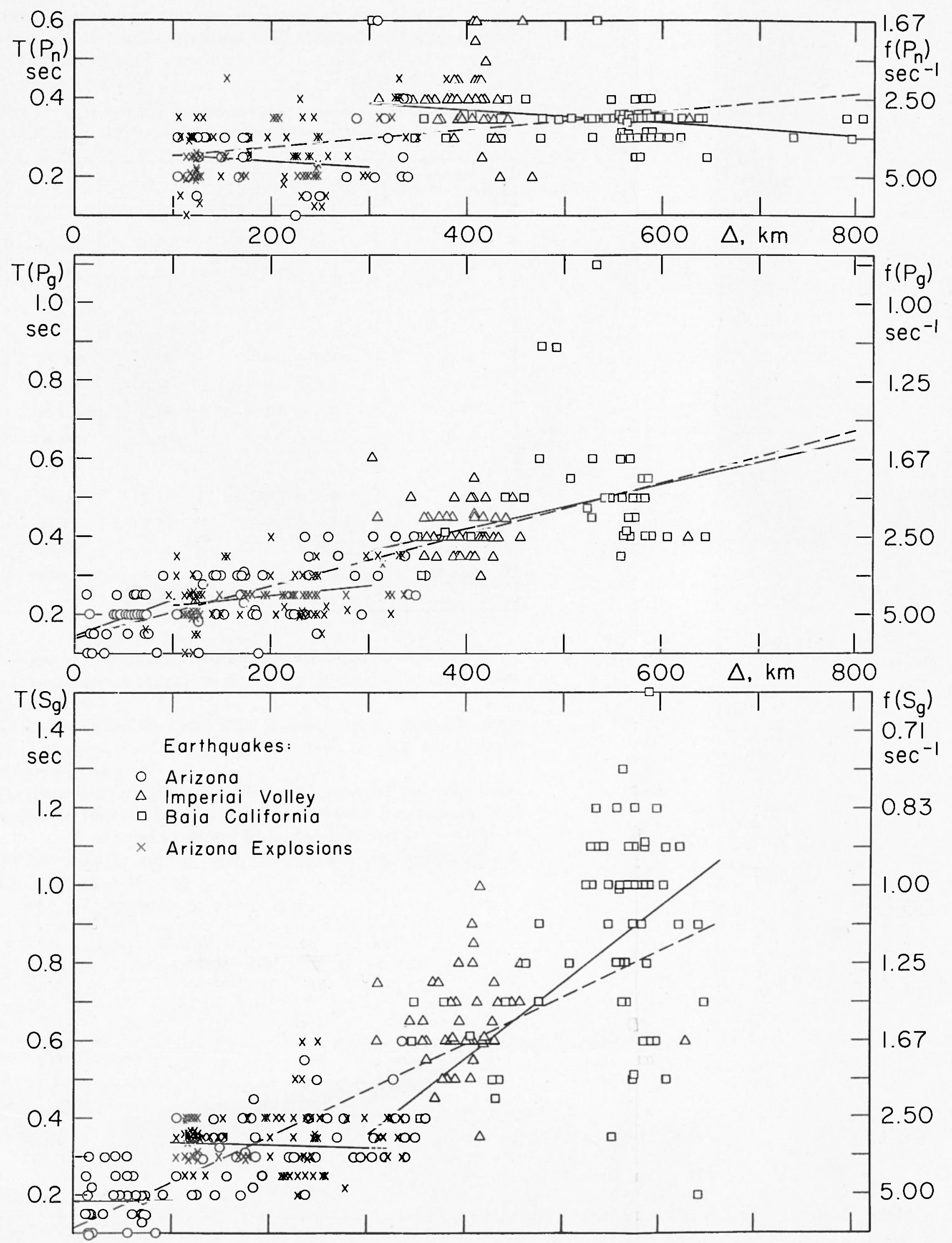

Fig. 5 - Period versus epicentral distance of $P n$-waves, $P g$-waves and $S g$-waves. $f=$ frequency $=1 / T$. 
REgIONAL SEISMICITY AND SEISMIC WAVE EROPAGATION, ETC. 381

at $300 \mathrm{~km}$, the changes of slope or jumps at that distance in the period-distance diagrams supporting each other for all three kinds of waves.

Table III - Least-square solutions For period-distance Relations (Fig. 5): $T(x)-a+b \Delta$, wrtir $T$ in sec and $\Delta$ in $\mathrm{km}$.

\begin{tabular}{|c|c|c|c|c|}
\hline$x$ & $\Delta$ & $a$ & $b \times 10^{+4}$ & $\begin{array}{c}\text { Correlation } \\
\text { between } T \text { and } \Delta\end{array}$ \\
\hline \multirow{3}{*}{$P n$} & $100-800$ & 0.23 & $+2.2 \div 0.3$ & +0.17 \\
\hline & $100-300$ & 0.27 & $-1.6 \pm 1.2$ & 0.02 \\
\hline & $300-800$ & 0.44 & $-1.6 \pm 0.6$ & 0.05 \\
\hline \multirow{4}{*}{$P g$} & $14-640$ & 0.14 & $+6.6 \pm 0.4$ & 0.58 \\
\hline & $14-100$ & 0.14 & $+8.6 \pm 3.6$ & 0.16 \\
\hline & $100-300$ & 0.20 & $+2.5 \pm 1.1$ & 0.05 \\
\hline & $300-640$ & 0.19 & $+5.7 \pm 1.3$ & 0.16 \\
\hline \multirow{4}{*}{$S g$} & $14-640$ & 0.11 & $+12.1 \pm 0.6$ & 0.64 \\
\hline & $14-100$ & 0.19 & $+0.3 \pm 4.6$ & 0.00 \\
\hline & $100-300$ & 0.34 & $-0.4 \pm 2.5$ & 0.00 \\
\hline & $300-640$ & -0.21 & $+19.8 \pm 1.4$ & +0.57 \\
\hline
\end{tabular}

The period discontinuities of $P n, P g$ and $S g$ at $100 \mathrm{~km}$ and about $300 \mathrm{~km}$ should have a bearing on the energy attenuation of these waves (see Section 5.2).

No dispersion for $S g$-waves could be ascertained. Thus, the large scatter of $S g$-periods of distances greater than $300-350 \mathrm{~km}$ must be due to another factor.

The period of the $P^{*}$-wave, which was recorded especially from earthquakes in Imperial County, was fairly constant for distances from about 300 to $450 \mathrm{~km}$ and amounted to $0.40 \pm 0.05$ sec.

No difference in periods from earthquakes and explosions was found. 


\section{3. - Duration of the $S g-p h a s e$.}

We define the duration of the wave train $t_{\Delta}$ at the epicentral distance $\Delta$ as the time from the beginning of the corresponding phase up to the decrease of its amplitude below $1 / \mathrm{e}(\simeq 1 / 3)$ of its maximum value. The duration was measured for $S g$ and $P g$-waves. The measurements ean only be approximate due to the complexity of the records.

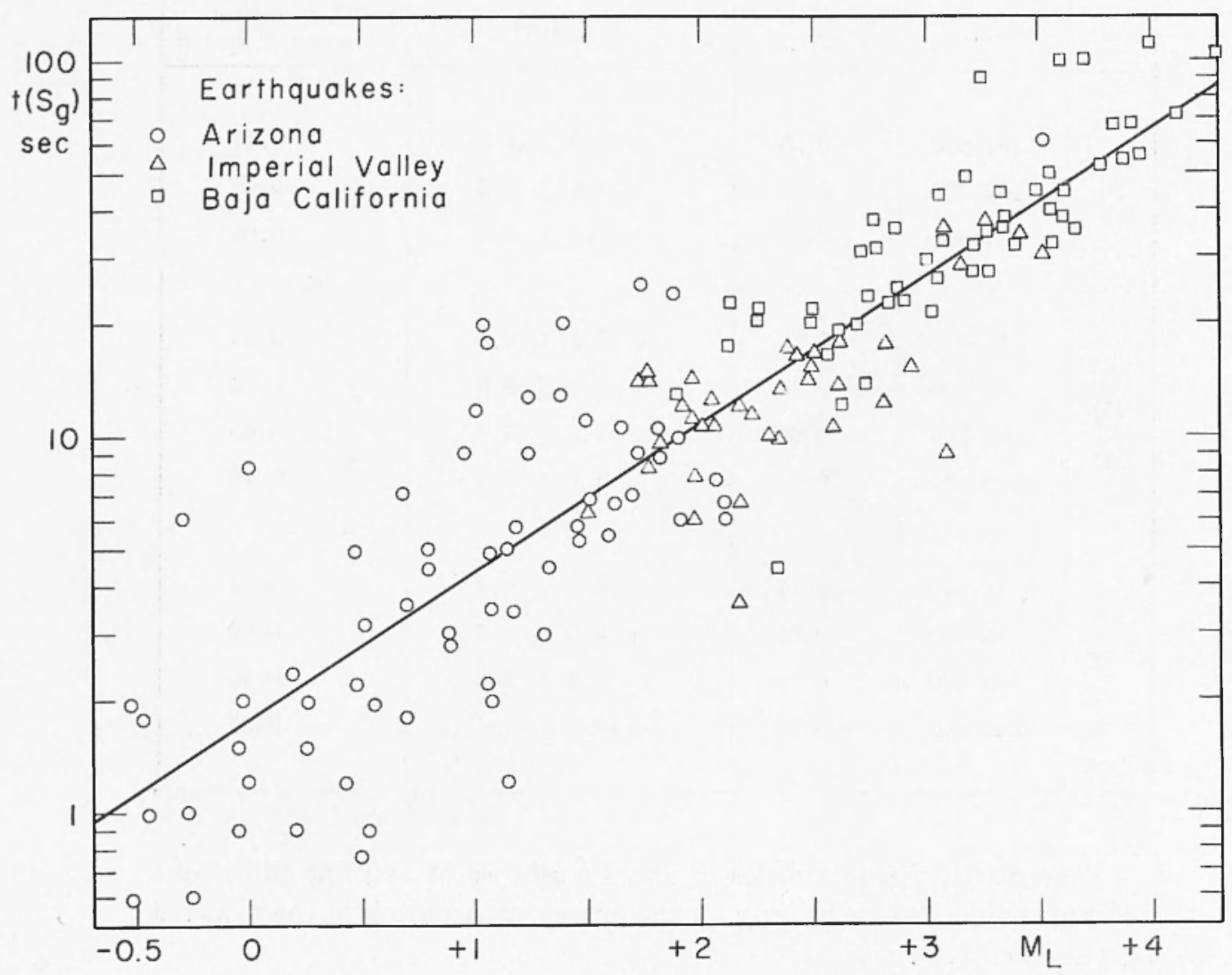

Fig. 6 - Duration of $S g$-phase as function of magnitude.

Whereas the durations of the $S g$ and $P g$-waves as function of epicentral distance display a large scatter, a clear dependence of the $s q$-phase on the magnitude could be found, as shown in Fig. $6 . \Delta$ least-square approximation of the data yields:

$$
\log t_{\Delta}(S g)=0.254+(0.391 \pm 0.016) M_{L}
$$


in the magnitude range $-0.7 \leqslant M_{L} \leqslant+4.3$ and where $t_{A}(S g)$ is expressed in sec. The equation is shown as a solid line in Fig. 6 .

The duration data were arranged according to distance classes of $50 \mathrm{~km}$. In all distance classes the same relation of duration to magnitude was found. This is in agreement with Gutenberg and Richter (1956a). Thus, the duration of the $S q$-phase is independent of distance in the investigated range:

$$
t_{\Delta}(S g)=t_{K}(S g)
$$

$\Pi$ is any distance in the range considered.

No corresponding least-square approximation for the duration of the $\mathrm{Pg}$-phase seems justified, because of a considerable seatter of the data. As no contrary information is found, we shall assume in the following that the ratio of the duration of the $S q$-phase to the duration of the $P g$-phase, $t_{\Delta}(S g) / t_{\mathcal{A}}(P g)$, is independent of magnitude.

There are four possible factors which may influence the duration of the $S q$-phase:

(a) dispersion;

(b) attenuation;

(c) source mechanism;

(d) lateral refraction and reflexion.

If dispersion of the $S q$-phase is present, even with no measurable change of period as in the case of a dispersion curve almost parallel to the velocity axis, the duration increases with epicentral distance. The attenuation of the $S q$-phase diminishes the duration of the wave train with epicentral distance. As no change of the $S g$-wave duration with distance was found, the factors mentioned either amnililate each other or their ratio is independent of the epicentral distance.

Therefore the increase of $S g$-wave duration with magnitude is probably due to items (c) and (d). The duration of the $S g$-wave is longer than any reasonable duration of rupture along the fault plane during an earthquake with magnitude $M_{L}$. The problem of the duration of seismic wave trains is old and no satisfactory explanation has been presented so far. Different hypotheses have been proposed or excluded (Jeffreys 1931, Tatel \& Tuve 1954, Tatel 1954). A final judgement requires a special study. 


\section{5. - WAVE ENERGY.}

\section{1. - Ratio of $\mathrm{Sg}$ to Pg-wave energy.}

The seismic wave energy from a point source in a homogeneous medium, recorded at a distance $h$, equal to the focal depth of the source, is:

$$
E_{h}(x)=2 \pi^{3} \varrho h^{2} v(x) \int_{\dot{\mathbf{j}}}^{t_{h}(x)}\left[\frac{\bar{A}_{h}(x)}{T_{h}(x)}\right]^{2} d t
$$

where $(x)$ refers to the kind of wave considered, $v(x)$ is the group velocity of the corresponding wave, $t_{h}(x)$ the duration of the wave train at distance $h$, $A_{h}(x), T_{h}(x)$ the amplitude and the period of the wave at distance $h$, $\varrho$ the density of the medium (Gutenberg \& Richter 1942, 1956a, b).

In formula [5.1] allowance is made for the mean kinetic and potential energies in the wave train and the effect of the free surface. Assuming that no absorption takes place on the way from the focus up to a distance $h$, the formula gives the seismic energy radiated from the source.

The $S g$ and $P g$-waves carried most of the seismic energy in all investigated shocks.

The maximum amplitudes $A_{4}$ were measured within 10 sec at most after the beginning of the phase together with the corresponding periods $T_{1}$. We used the horizontal component of the $S g$-wave and the vertical component of the $P g$-wave. It is reasonable to assume for $S q$-waves that the vertical component is half of the resaltant horizontal component, and for the $P q$-waves that the vertical and horizontal components are equal. We then get for the ratio of the total amplitudes $\bar{A}_{\Delta}(x)$ to the measured amplitudes $A_{J}(x)$ :

$$
\begin{aligned}
& k(S g)=\frac{\bar{A}_{\Delta}(S g)}{A_{\Delta}(S g)}=1.12 \\
& k(P g)=\frac{\bar{A}_{\Delta}(P g)}{A_{\Delta}(P g)}=1.41
\end{aligned}
$$

The duration $t_{\Delta}$ of the wave trains was measured until the amplitude decreased below $1 / e$ of its maximum value (see Section 4.3). We assume that the energy deficit from taking only that part of the wave train into 
account is compensated by the energy surplus from taking the maximum amplitude throughout the entire duration $t_{\Delta}$.

The energy of the $S g$ and $P q$-waves at distance $h$ will then be:

$$
\begin{aligned}
& E_{h}(S g)=2 \pi^{3} \varrho h^{2} v(S g)\left[\frac{A_{h}(S g)}{T_{h}(S g)}\right]^{2} t_{h}(S g)[k(S g)]^{2} \\
& E_{h}(P g)=2 \pi^{3} \varrho h^{2} v(P g)\left[\frac{A_{h}(P g)}{T_{h}(P g)}\right]^{2} t_{h}(P g)[k(P g)]^{2} .
\end{aligned}
$$

If $A_{\Delta}, T_{\Delta}$ and $t_{\Delta}$ are known as functions of distance, the energy at the source $E_{h}$ can be calculated from the energy $E_{\mathcal{A}}$ recorded at epicentral distance $A$.

Fig. 7 shows the ratio of the maximum particle velocities, $A_{\Delta} / T_{\Delta}$, for $S g$ and $P g$-waves as a function of epicentral distance. Under the above assumptions, this ratio is proportional to the square root of the ratio of the $S g$-wave energy, $E_{A}(S g)$, to the $P g$-wave energy, $E_{A}(P g)$ :

$$
\frac{A_{\Delta}(S g) / T_{\Delta}(S g)}{A_{\Delta}(P g) / T_{\Delta}(P g)}=\left[\frac{v(P g)}{v(S g)} \cdot \frac{t_{\Delta}(P g)}{t_{\Delta}(S g)}\right]^{1 / 2} \cdot \frac{k(P g)}{k(S g)}\left[\frac{E_{\Delta}(S g)}{E_{\Delta}(P g)}\right]^{1 / 2}
$$

As this ratio is composed by 4 values determined by measurement, it will scatter. Nevertheless, averaging the ratio in intervals of $50 \mathrm{~km}$ epicentral distance reveals some characteristic features:

(a) the ratio [5.6] amounts to about 8:1 close to the epicentre and at a distance of about $600 \mathrm{~km}$. In the first case this must be related to the focal process, in the second to the different propagation of the two kinds of waves.

(b) the ratio [5.6] has a distinct minimum equal to $2: 1$ at about $100 \mathrm{~km}$.

The general trend of the curves in Fig. 7 can be given the following explanations, arranged in order of probable importance:

(a) different attenuation of $P g$ and $S g$, the $S q$-attenuation being the strongest in the first $100 \mathrm{~km}$ but decreasing below the value of the $P q$-attenuation at greater distances. This seems likely considering the large percentage of high-frequency motion in $S g$ close to the source.

(b) the minimum around $100 \mathrm{~km}$ distance can partly be traced back to the corresponding period increase of 0.15 sec at that distance for $S g$ with no corresponding period change for $P g$ (Fig. 5). This

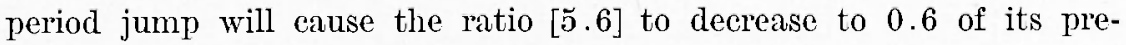
vious value. 


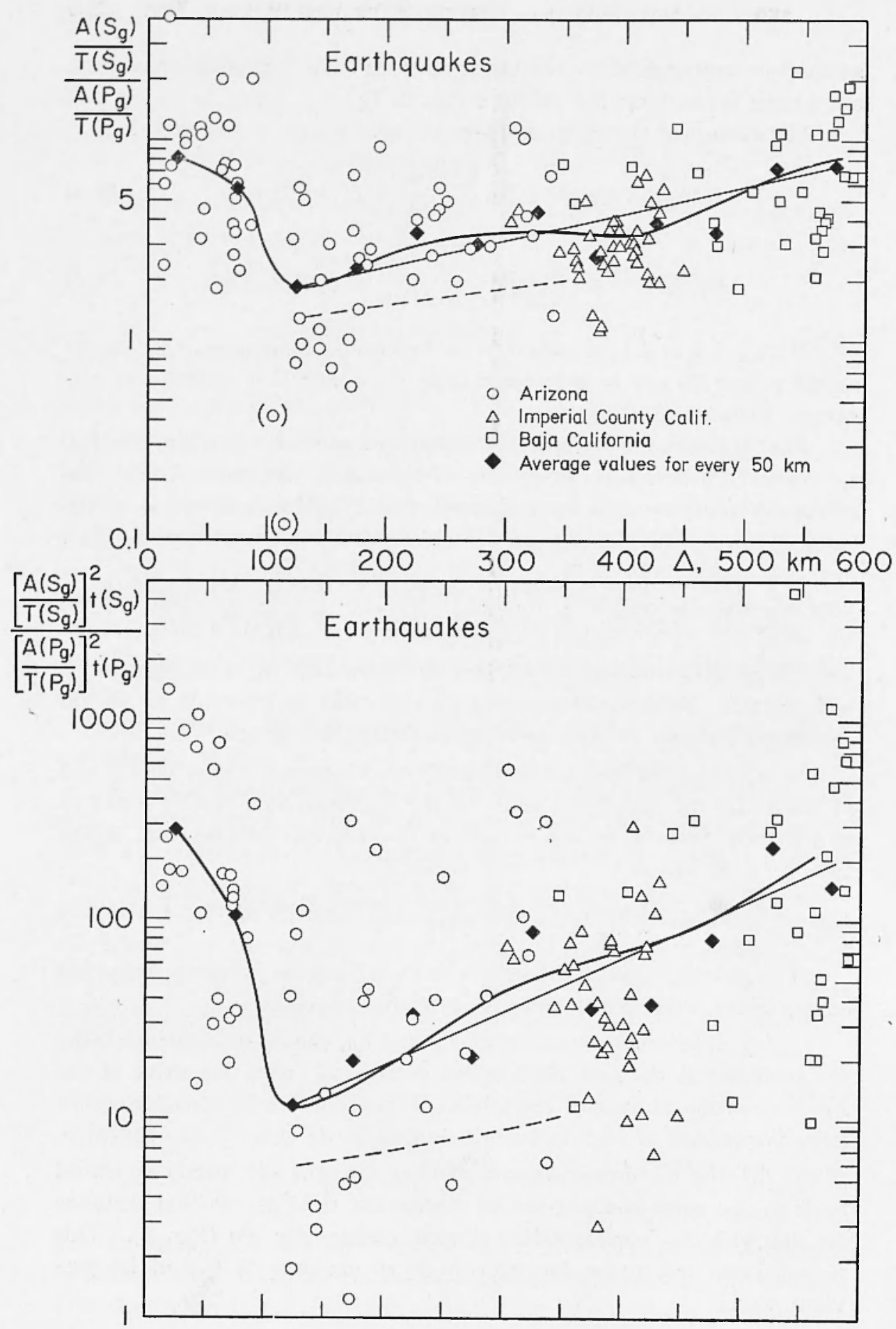

Fig. 7 - Ratios $A_{\Delta}(S g) / T_{\Delta}(S g): A_{\Delta}(P g) / T_{\Delta}(P g)$ and $\left[A_{\Delta}(S g) / T_{\Delta}(S g)\right]^{2}$ $t_{\Delta}(S g):\left[A_{\Delta}(P g) / T_{\Delta}(P g)\right]^{2} t_{\Delta}(P g)$ for earthquakes versus distance. 


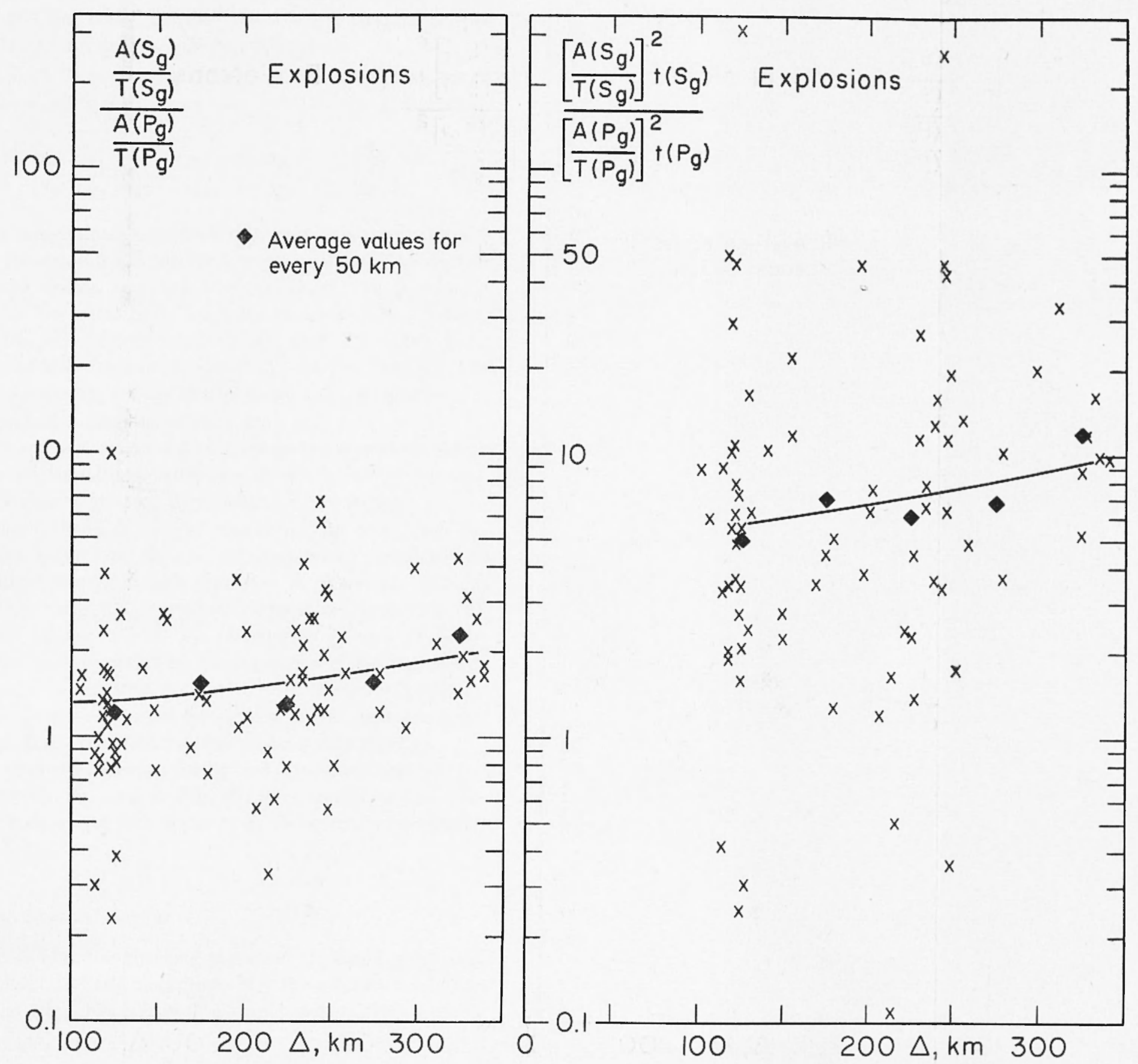

Fig. 8 - Ratios $A_{\Delta}(S g) / T_{\Delta}(S g): A_{\Delta}(P g) / T_{\Delta}(P g)$ and $\left[A_{\Delta}(S g) / T_{\Delta}(S g)\right]^{2} t_{\Delta}(S g)$ : $\left[A_{\Delta}(P g) / T_{\Delta}(P g)\right]^{2} t_{\Delta}(P g)$ for explosions versus distance. 
(c) constructive interference between $P g, P n$ and $P^{*}$ at the crossover distance near $100 \mathrm{~km}$ could increase the $P$-wave amplitude and thus contribute to the minimum around that distance.

Fig. 7 also shows [5.7] proportional to the ratio of the energies of the $S g$ - and $P g$-waves after introducing the duration $t_{\Delta}$ of the wave trains:

$$
\left.\frac{\left[A_{\Delta}(P g) / T_{\Delta}(S g)\right]^{2} t_{\Delta}(P g)}{\left[A_{\Delta}(S g) / T_{\Delta}(S g)\right]^{2} t_{\Delta}(S g)}=\frac{v(P g)}{v(S g)} \mid \frac{k(P g)}{k(S g)}\right]^{2} \frac{E_{\Delta}^{\prime}(S g)}{E \Delta(P g)} .
$$

Here, six quantities determined experimentally are combined, four of them in the second power, and the scatter is considerable. The characteristic features found above, however, are confirmed. In particular, close to the epicentre the ratio [5.7] amounts to about 280. Taking into account the ratio of the velocities of $S g$ and $P g$-waves from Table I, i. e. 0.56, and the ratios [5.2] and [5.3], we find that close to the epicentre the $S$-wave energy is about 100 times that of the $P$-wave. The nearest epicentre had a distance of $14.4 \mathrm{~km}$.

Consequently, in our epicentral distance range the $P g$-wave energy can be disregarded in comparison with the $S g$-wave energy for any calculation of seismic energy emitted by the earthquake focus.

Fig. 8 shows the ratio [5.6] of the maximum $S g$ and $P g$-wave particle velocities for explosions in the distance range from 100 to $340 \mathrm{~km}$. Only a slight increase with distance is observed. Similar features are seen for the ratio [5.7] proportional to the energies (Fig. 8). Considering the ratio of the $S g$ to $P q$-velocity [5.2] and [5.3], as before, we see that the energy carried by the $S g$-waves is still prevailing, but amounts in average to less than 3 times that carried by $P q$-waves. This feature was used as one of the criteria to distinguish in some cases between earthquakes and explosions in the present investigation.

The ratio of the particle velocities for $S g$ and $P g$-waves was plotted as function of magnitude, as seen in Fig. 9. The scatter of the data is large, and no dependence of this ratio upon the earthquake magnitude can be concluded.

\section{2. - Attenuation of $S g-$ wave energy.}

If a relationship is found connecting the ratio $A_{\Delta}(S g) / T_{\Delta}(S g)$ with the epicentral distance $\Delta$ and the magnitude $M_{L}$, the attenuation of the $S g$-wave can be found from recordings of a single station, just as well as of an array station. 
Here, a dependence in the following form is assumed:

$$
\log \left[\frac{A_{\Delta}(S g)}{T_{\Delta}(S g)} \Delta^{n}\right]=X+Y M_{L}
$$

$n, X, Y$ are constants.

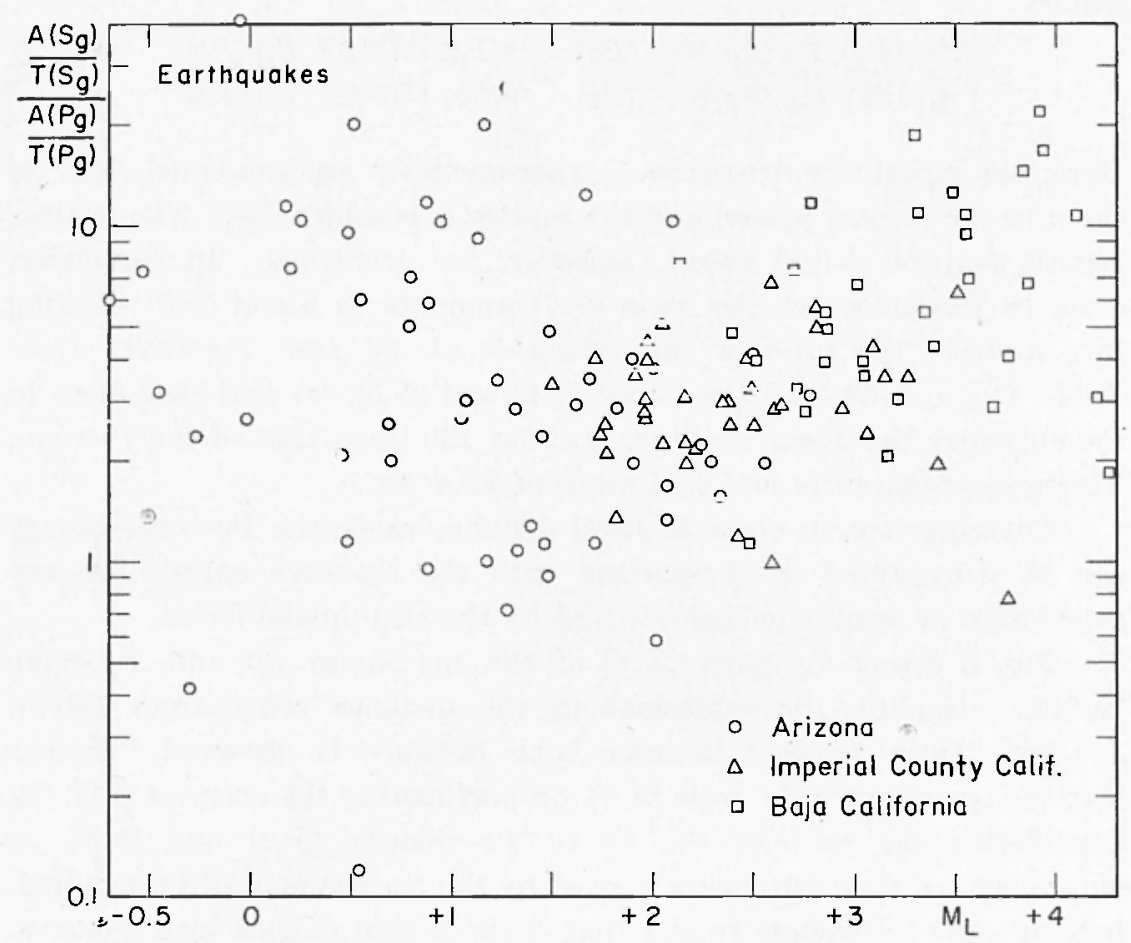

Fig. 9 - Ratio $A_{\Delta}(S g) / T_{\Delta}(S g): \Lambda_{\Delta}(P g) / T_{\Delta}(P g)$ for earthquakes versus magnitude.

The factor $\Delta^{n}$ accounts for both the geometrical spreading and the absorption. An attenuation according to $\Delta^{n}$ was found by Gutenberg \& Richter (1942), who noticed that

$$
\frac{A_{\Delta}(S g)}{T_{\Delta}(S g)} \Delta^{n}
$$

with $n=2$ was constant for an earthquake with a certain magnitude, recorded at different distances. Lampson (1946) demonstrated that an expression of the form [5.9] is constant for explosions. The observed decrease of amplitude ranges from the inverse third power at short 
epicentral distances to an inverse first power at large distances. A number of numerical values was compiled by Howell (1963).

Theoretically it is more correct to express the attenuation in the form

$$
\frac{A_{\Delta}(x)}{T_{\Delta}(x)}=\frac{A_{h}}{T_{h}}-\frac{(x)}{(x)} e^{-\alpha \Delta} \Delta^{-n},
$$

where $\alpha$ is the absorption coefficient and $n$ is equal to 1 for body waves and $1 / 2$ for guided waves.

But if the amplitude $A_{\Delta}(x)$ is associated with the maximum amplitude at any distance, the term involving $\alpha$ in [5.10] is usually omitted, and both the geometric spreading and absorption are expressed by the exponent $n$, as in [5.8] (Howell 1963).

Differentiating [5.8] with respect to $M_{L}$, we find

$$
x=\frac{a \log \left[A_{\Delta}(S g) / T_{\Delta}(S g)\right]}{d M_{L}}
$$

to be independent of the exponent $n$ for all distances where [5.8] is satisfied. Only the constant factor $X$ will be affected by the exponent $n$. By trial, we found the observational data to be best fitted by $n=2$. No single $X, Y$ - set, however, was acceptable for the entire magnitude and distance range. From Fig. $10 a$ we have the following least-square approximation for earthquakes and explosions in Arizona:

$$
\log \left[\frac{A_{\Delta}(S g)}{T_{\Delta}(S g)} \Delta^{2}\right]=7.183+(0.890 \pm 0.026) \lambda \Lambda_{L}
$$

in the magnitude range $-0.7 \leqslant M_{L} \leqslant+2.4$ and distance range $14 \mathrm{~km} \leqslant \Delta \leqslant 3 \pm 0 \mathrm{~km}$. From Fig. $10 b$ we have for earthquakes in Imperial County and Baja California:

$$
\log \left|\frac{A_{\Delta}(S g)}{T_{\Delta}(S g)} A^{2}\right|=6.941+(0.801 \pm 0.018) M_{L}
$$

in the magnitude range $+1.5 \leqslant M_{L} \leqslant+4.9$, and distance range $310 \mathrm{~km} \leqslant \Delta \leqslant 640 \mathrm{~km}$. $A_{\Delta}$ and $\Delta$ are given in $\mathrm{cm}, T_{\Delta}$ in sec. Equations of this form are in good agreement with the equation for the perceptibility limit (Fig. 3) at least for positive magnitudes.

Comparing the formulas [5.12] and [5.13] with [5.4] we notice that $S q$-wave energy decreases with the 4 th power of the distance. As the $S g$-wave is a guided wave, the energy attenuation due to geometrical spreading is proportional to $\Delta$; the absorption of energy will thus be proportional to $\Delta^{3}$. 
Besides that, at an approximate distance of $325 \mathrm{~km}$ we observe a sudden increase of attenuation. A similar change in attenuation at an epicentral distance of somewhat above $300 \mathrm{~km}$ was found in other parts of the world (Bune \& al. 1960, Kárnik 1962). Therefore the discontinuity in attenuation, as seen from Fig. 10a,b, is unlikely to be caused by regional differences in the crustal structure between Arizona on one

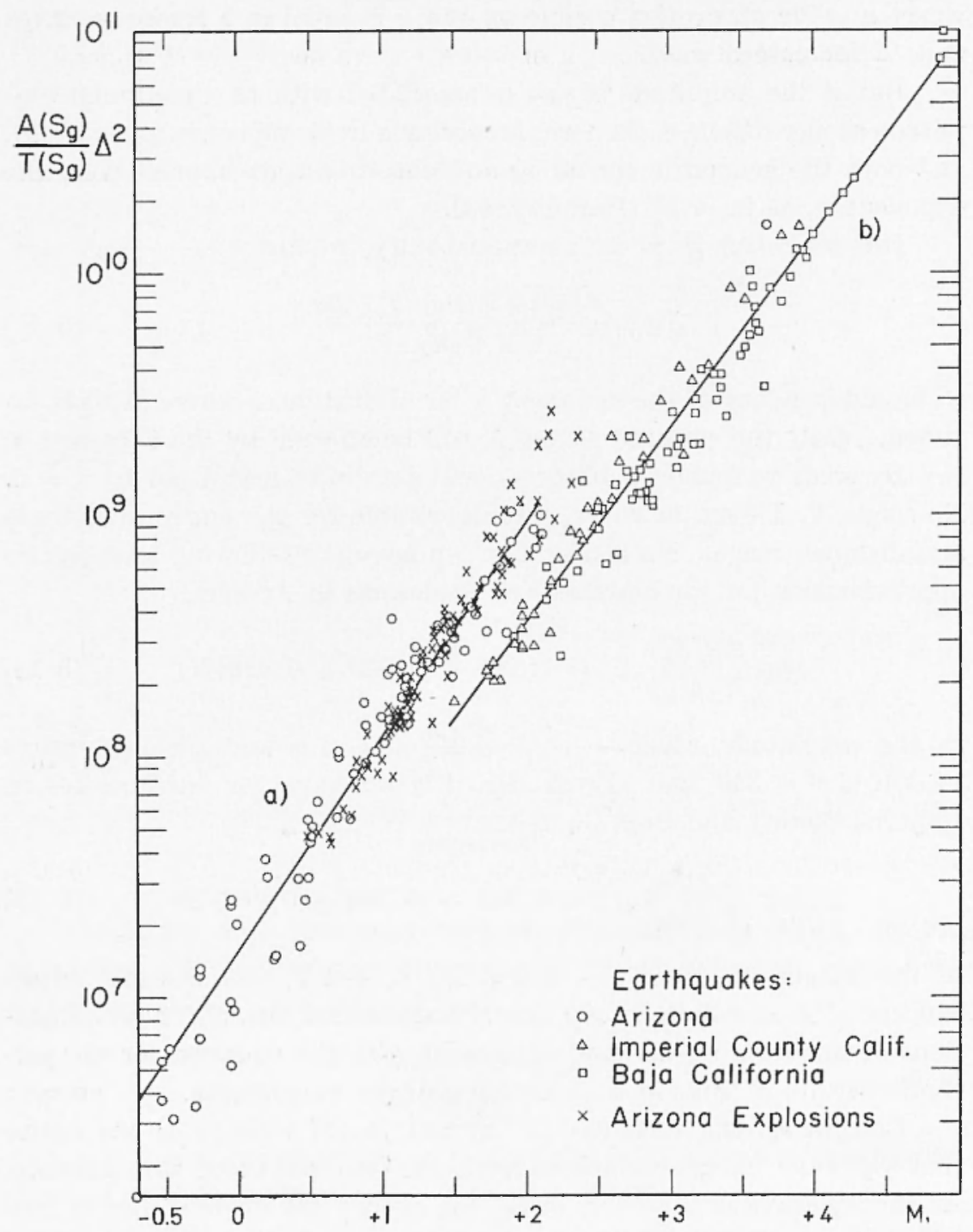

Fig. 10 - Attenuation for $a$ ) earthquakes and explosions in Arizona, $b$ ) earthquakes in Imperial County and Baja California. CGS-units are used. 
side and Imperial County and Baja California on the other. It is rather the propagation mode of $S q$-waves, which causes the discontinuity in the attenuation.

The sudden increase in attenuation at this distance is manifested by the decrease of $X$ in [5.8], amounting to 0.41 at $M_{L}=+.2 .0$ as seen from the formulas [5.12] and [5.13] and Fig. 10a, b. This corresponds to a decrease of the ratio $A_{\mathcal{J}}(S g) / T_{J}(S g)$ by a factor of 2.57 or to a decrease of the energy of the $S g$-wave nearly seven times. It seems probable that this is connected with the rapid increase in $S g-$ wave period at the distance of $300-350 \mathrm{~km}$ (Fig. 5).

The sudden increase of $S g$-wave periods at a distance of $100 \mathrm{~km}$ (Fig. $5 c$ ) indicates another discontinuity in attenuation. Unfortunately, the data are too scanty for a direct estimate of the decrease in $A_{\Delta}(S g) / T_{\Delta}(S g)$ at this distance.

\section{3. - Seismic energy released in an earthqualie.}

Knowing the attenuation and the duration of the $S g$-wave as function of magnitude, the seismic energy released at the focus of an earthquake with magnitude $M_{L}$ can be determined. We have from [5.4], neglecting the insignificant factor $k(S g)$ :

$\log E_{h}(S g)=\log \left[2 \pi^{3} \varrho v(S g)\right]+2 \log h+2 \log \left[A_{h}(S g) / T_{h}(S g)\right]+\log t_{h}$.

Taking $\varrho=2.7 \mathrm{~g} / \mathrm{cm}^{3}$ (Gutenberg \& Richter 1956a), assuming $h=14 \mathrm{~km}, v(S g)=3.25 \mathrm{~km} / \mathrm{sec}$ (Table I), and substituting [4.1] and [5.12] with $\Delta=h=14 \mathrm{~km}$ into [5.14], we obtain:

$$
\log E_{h}(S g)=10.06+(2.17 \pm 0.07) M_{L}
$$

for the magnitude range $-0.7 \leqslant M_{L}<+2.4$, and distance range $14 \mathrm{~km} \leqslant \Delta \leqslant 340 \mathrm{~km}$. The attenuation formula [5.13] cannot be extrapolated to epicentral distances lower than $310 \mathrm{~km}$, without taking into account the sudden increase in attenuation at about that distance. Compensation for that loss of seismic energy yields a magnitude-energy formula, practically equal to [5.15]. Formula [5.15] is then valid in the magnitude range $-0.7 \leqslant M_{L} \leqslant+4.9$ and distance range 14 $\mathrm{km} \leqslant \Delta \leqslant 640 \mathrm{~km}$.

Although the magnitude of an earthquake is not affected by it, the discontinuity in attenuation between $300 \mathrm{~km}$ and $350 \mathrm{~km}$ causes a 
considerable difference of seismic energies recorded at two epicentral distances, slightly below and above this distance range.

It is of interest to compare the magnitude-energy formula [5.15] for local earthquakes with the corresponding formula for teleseisms:

$$
\log E=9.9+1.9 M_{L}-0.024 M_{L}
$$

See Richter (1958, p. 366). We find that $E_{h}(S g) / E$ is approximately 130 for $M_{L}=5.0$, i. e. at a point where both formulas are expected to be valid. This may seem to be a large discrepancy whereas a comparison with an energy formula deduced from [5.13] gives almost perfect agreement $\left(E_{h}(S y) / E=6\right)$. Still, it does not appear to be excluded that, at least in some cases, earlier energy estimates could be somewhat low because of insufficient information on the very high attenuation, especially of $S y$, near the source (see Section 5.1).

\section{6. - Discussion.}

TFSO is one of the most sensitive seismograph stations continuously operated. The effective increase of the sensitivity of a station entails that besides earthquakes a large number of artificial events is recorded, especially in regions with numerous quarries, like Arizona. This raises the problem of distinguishing between earthquakes and explosions in the range of small epicentral distances, up to several degrees.

The appearance of an explosion record does not in general allow an immediate separation from an earthquake. This may be seen from the Arizona earthquakes reported in the TFSO-bulletin for the time interval Sep. 15, 1963-Jan. 31, 1964. An arrangement of the reported events according to their origin time shows a clear maximum at about 4 p. m. local time, just before the working day is terminated and most explosions are fired. The maximum is equally well pronounced for reported California events, with the difference that the maximum occurs 1 hour later, due to the local time difference.

From our investigation we found that the most pronounced difference between earthquakes and explosions is the ratio of $S$ to $P$-wave energy. The nearest recorded explosion had an epicentral distance of $100 \mathrm{~km}$. It is surprising that the ratio of $S$ to $P$-wave energy amounts in average to as much as 5 (for earthquakes 10) and increases up to 10 
(for earthquakes 40 ) at $300 \mathrm{~km}$ distance (Fig. 7 ). This allowed us to exclude explosions from the study of the Arizona seismicity.

The $S$-waves in explosions are unexpectedly strong if compared with the $P$-waves. However, they are weaker in explosions than in comparable earthquakes. This is in analogy to surface waves from nuclear explosions where Rayleigh waves dominate and Love waves are of secondary importance (Toksöz, Harkiider \& Ben-Menahem 1965).

The discrimination of explosions and the study of local seismicity require accurate hypocentre determinations. For the epicentral distance and focal depth determination, local travel time tables of high precision are needed, giving the travel times even as function of azimuth. The accuracy in azimuth determination of an epicentre from a single array station is limited mainly by the spacing within the array and by the appearance of phases at different epicentral distances. The azimuth is difficult to determine accurately from a single array station, especially at distances beyond about $3^{\circ}$, considering horizontal refractions in the crust and upper mantle. The conditions would certainly be very much improved if two or three array stations are situated at optimal relative distances. On the basis of the measurements presented in this paper, we find that a reasonable lower limit of the relative distance between two or more array stations equipped with seismometers like TFSO, is $3^{\circ}$ : up to that distance the first events are sharp and the arrival times on different seismometers of the array can be determined with an accuracy up to 0.01 sec. The upper limit of the relative distance of two or more array stations depends on the lower magnitude limit of events desired to be recorded completely in number. From the perceptibility diagram (Fig. 3) it is seen that two or more array stations of TFSO-type, at a relative distance of $500 \mathrm{~km}$ would assure the number of earthquakes recorded to be complete down to magnitude +2.0 in the region between the stations.

The application of an array station to regional problems display some advantages as also shortcomings. The superiority of the seismographic array station over conventional stations results from:

(a) the high sensitivity of the single seismometers;

(b) the possibility to improve the signal-to-noise ratio;

(c) the regular spacing of seismometers;

(d) the possibility to process the data automatically if recorded on magnetic tape; 
(c) the convenience of operating the station limited to a relatively small site.

The main shorthcoming of the array station if compared with a network of conventional stations, is the limitation in accuracy in spite of the dimension of the array. This difficulty can be partially overcome by increasing the maximal dimension of the array, or better still, by using two or more array stations. Thereby each array can conveniently be composed of a simpler system of seismometers.

In our study the records from a selection of seismometers of TFSO were available on microfilm. Therefore the data could only be processed in the conventional way. Nevertheless, some new results on ecrtain problems concerning the rheology of the Earth's crust could be obtained.

From the pereeptibility diagram (Fig. 3) we conclude that it is essentially impossible to record local earthquakes with small magnitudes at distances greater than some critical distance. No increase of the signal-to-noise ratio can improve this. The only possible way to include small local earthquakes seems to be to record them at small epicentral distances.

From a complete recording of earthquakes in two sequences down to very small magnitudes, the recurrence diagrams (Fig. 4) were found to have a break at a magnitude of about +3.7 such that the rate of increase of the number of earthquakes with decreasing magnitude becomes smaller for magnitudes below this limit. This raises the question whether further breaks oceur at still smaller magnitudes.

In the light of this finding it seems problematic to extrapolate the recurrence diagram in any direction beyond the magnitude limits for which it has been found or to draw conclusions about the probable future occurrence of earthquakes. An extrapolation can be performed only if the coefficients in the recurrence formula [3.1] or [3.2] can be assumed to be constant also outside of the magnitude range investigated or if the change of these coefficients with magnitude is known. None of these conditions is fulfilled and an extrapolation can only be speculative. Therefore, our results do not support an idea, which has sometimes been expressed, that it would be possible to get a reliable information on long-term statistics of the seismicity of an area by recording a large number of very small shocks within a relatively limited time interval.

The attenuation of seismic waves may seem impossible to be studied from records of a single station, even an array station, since both the magnitude and epicentral distance change for every recorded earthquake. However, even in that problem the array station records have 
proved to deliver results comparable to those of a network of conventional stations. The propagation of seismic waves at shortest epicentral distances turned out to be complicated. The rapid increases of period at distances of 100 and about $325 \mathrm{~km}$ cause a sudden increase in the wave attenuation. This is especially clear for $S g$-waves, carrying most of the seismic energy. The knowledge of the attenuation pattern allowed a better estimation of the seismic energy released in local earthquakes.

\section{ACKNOWLEDGMENTS.}

This research was supported by the Contract AF-49 (638)-1337 of the Air Force Office of Scientific Research Projetes Agency Project VELA and the Contract $\triangle F$ 61(052)-588 of the Cambridge Research Laboratories of the Office of Aerospace Research, United States Air Force, through its European Office, as part of the Advanced Research Projects Agency's project VELA-UNIFORMI.

I am very much indebted to Professor Markus Båth, Director of the Seismological Institute, Uppsala, for enabling me to travel to the United States and stay at the Seismological Laboratory in Pasadena, where most of the present investigation was performed. I wish to express to Professor Markus Båth my most sincere gratitude for encouragement throughout the work and much helpful advice and valuable discussions, as also for assistance in framing the manuscript.

Professor Frank Press, Director of the Seismological Laboratory, Pasadena, proposed to me the subject of this investigation, supported it and contributed to it in a number of valuable discussions and read the first draft of the paper. I am grateful for this and I also like to express to Professor Frank Press my deep appreciation for making possible my temporary stay at the Seismological Laboratory in Pasadena.

My best thanks are extended to Professor Ch. Richter, Professor $\mathrm{Cl}$. Allen and Mr. L. Lenches, Pasadena, Mrr. A. MI. Rugg, Jr., Payson, Arizona, and Mr. B. Jansson, Uppsala, who contributed in various aspects of my research.

Seismological Institute, Uppsala, Sweden,

$$
\text { and }
$$

Division of Geological Sciences, California Institute of Technology, Pasadena, California, USA (Contribution 1325). 


\section{REFERENCES}

ASADA T., Observations of nearby microearthqualies with ultra sensitive seismometers. "J. Phys. Earth". 5, 83-113, (1957).

B\&ti MI., The elastic waves $\mathrm{Lg}$ and $\mathrm{R} g$ along Eurousiatic paths. "Arkiv f. Geof. ", 2, 295-342, (195 4 ).

B̊̊ti M., Channel waves in the earth's continental crust. "Scientia ", 56òme Annće, 1-8, (1962).

Berg J. W. Jr., Cook K. L., Naraxs H. D. and Dolan W. M., Seismic investigation of crustal structure in the eastern part of the Basin and liange Province. "Bull. Seism. Soc. Aru.". 50, 511.536, (1960).

Bune V. I., Gzovskis M. V. et al., Methods for a detailed study of seismicity. "Trudy Inst. Fiz. Zemli in. O. Iu. Shmidta", English Translation, No. 9 (176), (1960).

Dimest W. H., Steward S. W. and Roller J. C., Crustal structure from the Nevada test site to Kingman, Arizona, from seismic and gravity observations. “J. Geoph. Res.', 66, 201-214, (1961).

EaRdery A. J., Structural Geology of North America. Harper Brothers, New York, 1951.

Guteniberg B. and Riciten C. F., Earthquale magnitude, intensity, energy, and acceleration. "Bull. Seism. Soc. Am.", 32, 163-192, (1942).

Gutenderg 13. and Riciter C. F., Seismicity of the Earth and Associated Phenomena. Princeton University Press, 1954.

Gutenberg B. and Riciter C. F., Earthquale magnitude, intensity, energy, and acceleration. "Bull. Seism. Soc. Am.", 46, 105-146, (1956a).

Gutenberg B. and Riciter C. F., Magnitude and energy of earlhquakes. "Ann. di Geof.", IX, 1-15, (1956b).

IIOWELL B. F. Jr., Absorption of seismic waves. "VESTAC State-of-the-Art Report", The University of Michigan, (1963).

Jerfrers H., On the cause of oscillatory movement in seismograms: "IIonth. Not. R.A.S., Geoph. Supplement", II, No. 8, 407-416, (1931).

Jefrreys II. and Buldex K. E., Seismological Tables, Brit. Assoc. Advanc. Science, London, 1958.

KÁRNiK V., Amplitude-distance curves of surface waves at short epicentral distances $(\Delta<2000 \mathrm{~lm})$. "Studia Geoph. et Geodet.", 4, 340-346, (1962).

Lanpsox C. W., Final report on effects of underground explosions. "Nat. Def. Res. Comm. of the Office of Sci. Res. and Dev.", Report. No. A.479, (1946).

PAKISER I. C., Structure of the crust and upper mantle in the western United States. "J. Geoph. Res.", 68, 5747-5756, (1963). 
PAKISER L. C. and Hut. D. P., Crustal structure in Nevada and southern Idaho from nuclear explosions. "J. Geoph. Res.", 68, 5757-5766, (1963).

Press F., Crustal structure in the California-Nevada region. "J. Geoph. Res. ", 65, 1039-1051, (1960).

Press F. and Ewivg .I., Tuo slow surface waves across North America. "Bull. Seism. Soc. Am.", 42. 219-228, (1952).

Press F. and Gutenbenc B., Channel waves $\pi g$ in the earth's erust. "Trans. Am. Geoph. Union ", 37, 754-7566, (1956).

RICHTER (. F., An instrumental earthquake magnitude seale. "Bull. Seism. Soc. Am.", 25, 1-32, (1935).

Riciter (. F., Elementary Seismolog!g. W. H. Freeman \& Co.. San Francisco, 1958.

SAxprod A. R. and Horyes (. R., Hicroearthquales near Socorro, New Merico. "J. Geoph. Res.", 67, 4449-4459, (1962).

TATEr H. E., Note on the nalure of a seismogram II. "J. Geoph. Res.", 59. $289-294$, (1954).

Tated II. F. and Tuve M. A., Note on the nature of a seismogram. I. "J. Geoph. Res.', 59, 287-288, (1954).

TATes H. E. and Tuve M. A., Seismic exploration of a continental crust. "Geol. Soc. Am. Spec. Paper", 62, 35-50, (1955).

Toksöz M. N., Markrider I). G. and Bex-Menamex A., Determination of source parameters by amplitude equalization of seismic surface waves; 2. Release of tectonic strain by underground nuclear explosions and mechanism of earthquakes. "J. Geoph. Res.", 70, 907-922, (1965).

Townety S. D. and Aluen II. W., Descriptice catalog of earthqualies of the Pacific Coast of the United States 1769-1928. "Bull. Seim. Soc. Am.", 29, 1-297, (1939).

ITSU T., A statistical study on the oceurrence of aftershocks. "Geoph. Mag.", 30, $521-6066,(1961)$.

Wooldar1 G. P., Report of the Special Committee on the geophysical and geological study of continents 1950-51. "Trans. Am Geoph. Union", 32. $634-647,(1951)$. 